\title{
Correction to: Curriculum in International Contexts
}

\section{Correction to:}

A. Kumar, Curriculum in International Contexts, Curriculum Studies Worldwide, https://doi.org/10.1007/978-3-030-01983-9

The original version of the book was inadvertently published without incorporating some of the belated corrections provided by author, which have been now incorporated. The correction book has been updated with the changes. 